Article

\title{
An Experimental and Environmental Evaluation of Mortars with Recycled Demolition Waste from a Hospital Implosion in Rio de Janeiro
}

\author{
Thiago Melo Grabois ${ }^{1,2,3, *(1)}$, Lucas Rosse Caldas ${ }^{1,3}$, Nathália Rodrigues Julião ${ }^{1}$ \\ and Romildo Dias Toledo Filho ${ }^{1}$ (1) \\ 1 Civil Engineering Program, COPPE, Federal University of Rio de Janeiro, Rio de Janeiro 21941-972, Brazil; \\ lrc@coc.ufrj.br (L.R.C.); nathaliarodrigues@poli.ufrj.br (N.R.J.); toledo@coc.ufrj.br (R.D.T.F.) \\ 2 Programa de Pós-Graduação em Arquitetura PROARQ/FAU, Federal University of Rio de Janeiro, \\ Rio de Janeiro 21941-901, Brazil \\ 3 Faculty of Architecture and Urbanism, Federal University of Rio de Janeiro, Rio de Janeiro 21941-901, Brazil \\ * Correspondence: grabois@fau.ufrj.br
}

Received: 29 August 2020; Accepted: 9 October 2020; Published: 28 October 2020

check for updates

\begin{abstract}
Construction and demolition waste generation have increased significantly over the century, many times, as a result of obsolete buildings that lead the effort toward demolition. This paper investigates the environmental performance of mortars developed with recycled concrete from the partial building demolition of the Clementino Fraga Filho University Hospital in Rio de Janeiro, Brazil. Life Cycle Assessment is associated with experimental data to validate the application of the residue as an alternative to cement-based mortars. Natural river sand and recycled concrete aggregates, both at a micrometer scale, are employed in the production of four different mortars of compressive strength ranging $50 \mathrm{MPa}$. The aggregates' replacement rates defined are 15, 25, and 50\% in volume. The recycled microparticles' mineralogical composition was determined by SEM images and XRD analysis. In addition, the attached cement paste surrounding the original aggregate particle was quantified by chemical attack. Rheological and mechanical properties of the resulting mortars were assessed by the Vane spindle rheometer and uniaxial compressive strength experiments, respectively. The approach to mortars' environmental performance considered a cradle-to-gate scope using different sensitivity analysis parameters. We demonstrated the feasibility of developing an eco-efficient mortar taking advantage of rarely applied recycled particles. Compressive strength and environmental performance (particularly, the ozone layer depletion potential and abiotic resource depletion potential categories) increased with the aggregate replacement rate. In addition, the rheological results provided relevant data, still insufficient to recycled aggregate mortars, presenting an exponential increase of yield stress with effective water to cement ratio.
\end{abstract}

Keywords: recycled concrete aggregate; attached cement paste; building demolition; environmental performance; life cycle assessment

\section{Introduction}

Recycling construction and demolition waste (CDW) as aggregates for cement-based materials minimize the environmental impacts of landfill disposal and overcomes the lack of natural resources [1]. Crushing procedures of CDW, e.g., in the recycled coarse aggregates production, generate large amounts of fine particle fractions, smaller than $4 \mathrm{~mm}$ [2,3]. In this context, several researchers have studied the possibility of replacing natural by recycled fine aggregates from CDW. Most of these studies limited the subject to the comprehension of physical and mechanical aspects of the recycled aggregate mortars [4-6]. Overall, they have shown satisfactory results. On the other hand, recycled aggregates 
usually have a more angular surface than the natural ones and a high amount of fine particles, which is extremely relevant when studying the mortars' properties in a fresh state since its behavior changes fast and its casting operations occur at this state $[7,8]$. Although the fresh properties of mortars containing CDW are well documented, the studies often centered the discussion to consistency results [8-10] that usually exhibit workability losses when increasing the consumption of recycled aggregates in the mortars. Furthermore, relevant studies have recently addressed the rheological properties of mortars [11,12] and cement-based composites [13] containing very fine recycled aggregate particles. Duan et al. [11] presented a significant increase in the yield stress when increasing the consumption of recycled particles. This trend was also observed for flow measurements and plastic viscosity data. In a study with recycled aggregate particles of different sources, Lima et al. [12] showed the same increasing trend for both yield stress and viscosity even to mortars of constant consistency. Jiang et al. [13] showed that the incorporation of recycled sand considerably affects the yield stress results, while the viscosity of ultra-high performance mixtures remains unaffected.

Around 30\% of all industrial sand produced in Brazil goes to mortars' production, and most of it is concentrated in the Southern and Southeastern regions, mainly in the state of São Paulo [14]. In the last year, the natural sand availability has become an issue in some Brazilian cities, affecting the construction sector mainly concerning mortars' and concretes' production. This compelling scenario is yet more aggravating when considering the large housing deficit that persists [15] and needs urgently to be controlled in the coming years. Furthermore, the excessive consumption of the material by the preceding building activities can lead to the deterioration of riverbeds and landscapes. Therefore, the evaluation of CDW properties and its viability as an alternative aggregate, particularly replacing the fine particles at the whole scale of applicability, is an appropriate research topic to fulfill some of the remaining gaps in this field of study.

Fine-grained concretes and mortars, i.e., cement-based mixtures containing fine particles, predominantly at a micrometer scale, have been developed to a wide array of novel civil engineering applications. For instance, nonstructural concrete applications [16], fiber-reinforced [17], textile reinforced [18], high and ultra-high performance cement-based composites [13,19], and 3D printing technology [20] are some of the attractive possibilities that emerged as the next generation of infrastructure materials. Those were employed, among other things, as thin sheet components for building systems, supplementary structural reinforcement, structural rehabilitation, and building retrofitting.

Recent studies have applied the Life Cycle Assessment (LCA) approach for environmental performance evaluation of different products, processes, and services. The LCA is widely accepted by the scientific community among the methodologies that evaluate building materials, including those that incorporate solid waste into their production process [21,22]. Over the past decade, there has been a growing number of LCA researches related to CDW in building materials, especially those concerning the production of concretes and mortars [23,24]. Most of them showed that recycling this waste as a partial substitute for natural aggregates improves environmental performance.

In Brazil, numerous buildings have become obsolete, which consequently leads to efforts toward their renovation or demolition. For instance, the partial implosion of the University Hospital Clementino Fraga Filho-affiliated to the Federal University of Rio de Janeiro-took place in 2010 as a result of structural complications in the nonoccupied wing, representing the half-building demolition of a remarkable example of modern architecture. This two-phase procedure (initiated by a manual detachment of the two wings, followed by the implosion) generated a considerable amount of solid waste, i.e., piles of masonry and concrete debris [25]. Some of this waste has been used as recycled aggregates in Portland cement mortars and concretes [6,26]. Overall, the effects on the mix-design and mechanical properties demonstrated the feasibility of the recycled material for mixtures designed for structural applications. However, a share of it still needs a suitable destination, e.g., the fine particles originated during the crushing procedure of the rubble. Although this fact is environmentally relevant, 
the full characterization of the material behavior and its application are also essential to validate its purpose.

The research developed herein deals with a real demolition case study that focuses on generally rejected aggregate-size fractions. It is of great relevance since the number of obsolescent buildings is on the rise in many countries and the demolitions tend to consequently increase. Therefore, it is essential to evaluate the feasibility of recycling the generated waste technically and environmentally. Additionally, the study aligns with principles of the Circular Economy that should guide development plans in many countries, especially in emerging economies [27].

This paper aims to evaluate the effects of the recycled concrete aggregates-at a micrometer scale-originating from building demolition, on the environmental, rheological, and mechanical performances of mortars. Instead of limiting the study to experimental characterization data, the proposed approach also deals with the environmental performance to demonstrate the potential of its implementation. Therefore, contributing to overcome important state-of-the-art gaps, we first evaluate a demolition waste and demonstrate the feasibility of recycled aggregate particles rarely applied. Then, a more systematic analysis, using the LCA, considering different aspects in the sensitivity analysis, was carried out. The proposed approach can be applied in similar cases and stimulates the investigation of CDW from actual situations.

\section{Materials and Methods}

\subsection{Materials}

Brazilian high early strength Portland cement type according to ABNT NBR 16,697 [28] of $40 \mathrm{MPa}$ strength class and $3.16 \mathrm{~g} / \mathrm{cm} 3$ density, siliceous river sand, and deionized water were employed in the preparation of mortars.

The recycled concrete aggregate originates from the debris of the Clementino Fraga Filho University Hospital's partial implosion. Consistent details regarding the implosion procedure are described by Barreiro et al. [25], and the processing of the rubble, as well as its crushing and homogenization strategies to produce the recycled aggregates, were previously reported $[6,26]$. The mixtures studied herein are produced with aggregate microparticles of diameter ranging from 125 to $450 \mu \mathrm{m}$.

Table 1 summarizes the materials' chemical composition, bulk-specific gravity, according to ABNT NBR NM 52 [29], and water absorption, according to ABNT NBR NM 30 [30], as well as the morphological aspects of both aggregate types. Of particular interest is the high content of calcium $(11 \%)$ and aluminum oxide $(7.8 \%)$ in the silica $(66 \%)$ rich recycled sand, which evidences the presence of a cementitious layer covering the original aggregate particle. Furthermore, the low density and high-water absorption capacity of the recycled aggregate-about 5 times higher than the natural sand-are directly associated with this adhered cement paste.

Table 1. Physical and chemical characteristics of the natural and recycled aggregates.

\begin{tabular}{lcc}
\hline & Recycled Aggregate & Natural Aggregate \\
\hline Specific gravity $\left(\mathrm{g} / \mathrm{cm}^{3}\right)$ & 2.27 & 2.40 \\
Absorption (\%) & 7.00 & 1.53 \\
\hline Oxide composition by mass (wt.\%) & & \\
\hline $\mathrm{SiO}_{2}$ & 66.20 & \\
$\mathrm{CaO}$ & 11.10 & \\
$\mathrm{Al}_{2} \mathrm{O}_{3}$ & 7.80 & \\
$\mathrm{Fe}_{2} \mathrm{O}_{3}$ & 1.70 & \\
$\mathrm{~K}_{2} \mathrm{O}$ & 1.50 & \\
$\mathrm{Na}_{2} \mathrm{O}$ & 1.20 & \\
$\mathrm{MgO}^{\mathrm{O} O}$ & 1.10 & \\
$\mathrm{TiO}_{2}$ & 0.58 & \\
$\mathrm{P}_{2} \mathrm{O}_{5}$ & 0.22 & \\
\hline Loss on ignition & 0.21 & \\
\hline
\end{tabular}


Figure 1 shows the particle size distribution of the aggregates, emphasizing the size fraction between 0.15 and $0.425 \mathrm{~mm}$ that was extracted from the complete array of fine aggregate particles after mining (natural river sand), crushing (recycled debris), and sieving.

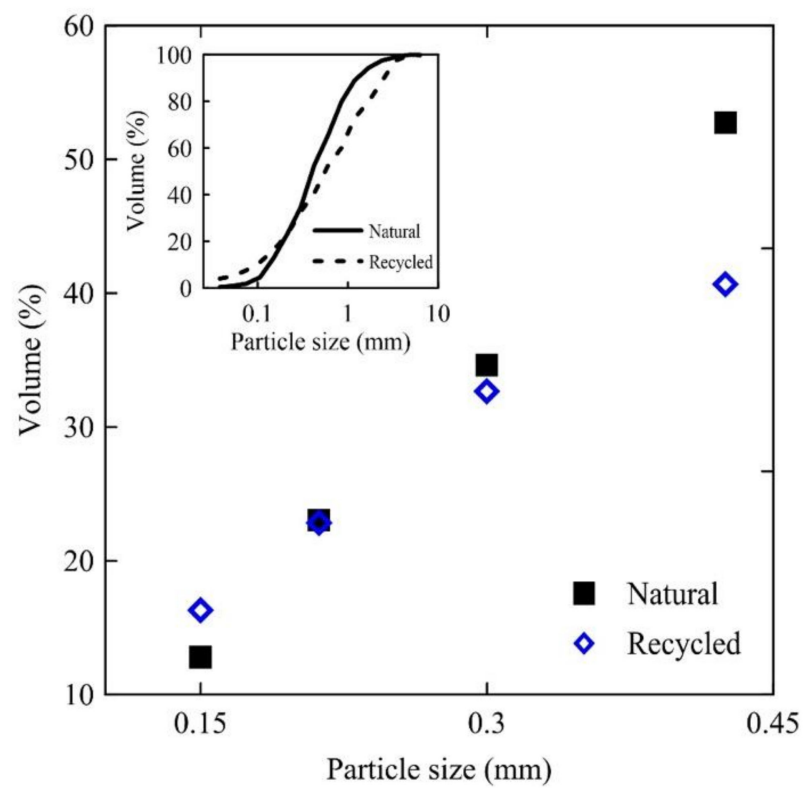

Figure 1. Particle size distribution of the aggregates. In the main panel, only the particle size fractions between 0.15 and $0.45 \mathrm{~mm}$ selected for this study. The upper left inset displays the particle distribution within the complete array of fine aggregates.

\subsection{Mineralogical Composition of the Recycled Concrete Aggregates by SEM Images}

A series of scanning electron microscopy (SEM) analyses are performed to qualitatively evaluate the mineralogical composition of the recycled concrete aggregates, since, in a general way, the recycled aggregate particles seem highly heterogeneous, mainly because two different mineral materials compose them: natural aggregates and alkaline cement paste (see, e.g., Figure 2).

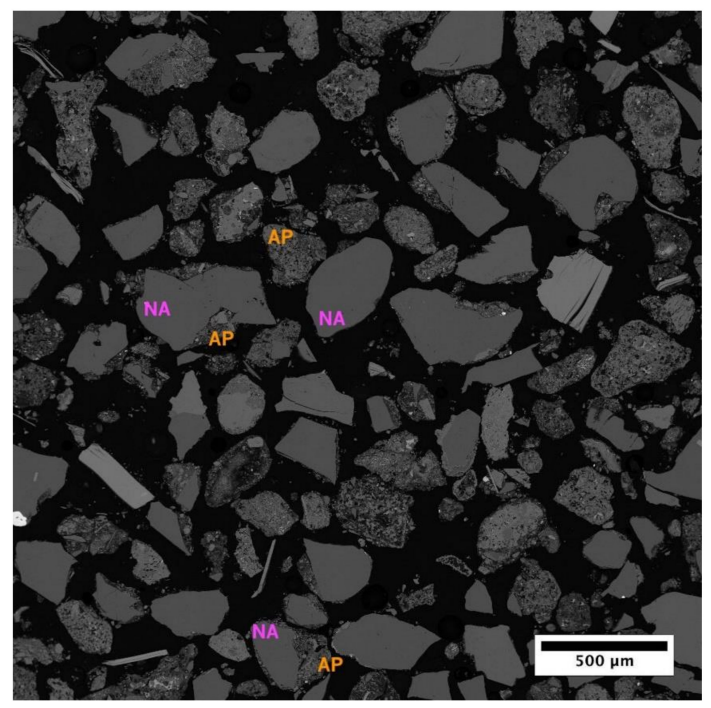

Figure 2. Typical SEM image of the recycled aggregate particles. Image size of $1024 \times 1024 \mathrm{px}$ $(2710 \times 2710 \mu \mathrm{m})$. The black background is the space between particles that are filled by epoxy resin, solid gray represents the natural aggregate (NA) particles, and the more heterogeneous gray zones are the attached cement paste (AP). 
The samples were segregated by a sieve series, and the fraction between 150 and $600 \mu \mathrm{m}$ was employed. The obtained samples were cold mounted with epoxy resin and subsequently ground and polished in a conventional metallographic approach. Then, the cross-sections were covered by evaporated carbon to make them conductive and suitable for SEM analysis [31].

For each sample, 10 fields, regularly spaced on the cross-sections, were imaged $(1024 \times 1024$ pixels with 8-bit digitization) through a specimen, scanning with a motorized stage, resulting in at least 500 particles per sample. The pixel size corresponds to $2.65 \mu \mathrm{m}$ with the applied magnification. An SEM LEO S440 was employed with a back-scattered electrons (BSE) detector, which produces images with atomic number contrast.

The image analysis procedure was performed by an automatic routine implemented in the Carl Zeiss Axiovision software. This routine separates the particles and measures some shape and texture parameters in each particle.

The particles were segmented, thresholding the grey level histogram using a fixed criterion. The careful image acquisition guaranteed that the brightness and contrast were reproducible and that the corresponding digital pixel values were stable. Thus, it was possible to use a fixed grey-level threshold, effectively automating this step.

Considering the shape characterization, no universal definition for the form of an object exists. Intuitively, the shape of an object can be described by comparing it with another one. Thus, in image analysis, the shape is commonly characterized by quantifying the differences between a given object and a reference shape.

In this analysis, only a qualitative comparison of the images was carried out, proving that the recycled aggregates present attached Portland cement paste on the original aggregate particle from crushed CDW (Figure 2), thus evidencing physical differences between natural and recycled particles, as previously discussed. In other words, this 2D view displays natural aggregate (NA) particles without surrounding attached cement paste (AP), while some others are partially or entirely covered by AP.

\subsection{Mineralogical Composition of the Recycled Concrete Aggregates by X-ray Diffraction}

X-ray diffraction analysis was performed on a Bruker-AXS D4 Endeavor diffractometer, with Co $\mathrm{k} \alpha$ radiation $(35 \mathrm{kV} / 40 \mathrm{~mA})$. Diffraction patterns were acquired from 5 to $80^{\circ}(2 \theta)$ at $0.02^{\circ}$ steps, with a counting time of $1 \mathrm{~s}$ per step. The identification of all the minerals was done with Bruker-AXS's DIFFRAC.EVA suite and PDF4 + 2012 relational database [32]. The aliquots for quantitative X-ray diffraction analysis were ground in a MacCrone oscillating grinder with agate grinding, mounted on the backload type support (for preferential orientation reduction), and analyzed on the X-ray diffractometer. An internal standard of $20 \%$ fluorite was used for the quantification of amorphous material.

Quantitative analyses using X-ray data were calculated using the total multiphase spectrum refinement method (Rietveld method) with Bruker-AXS Topas 4.2 software. The crystalline structure information of the refined phases was supplied by the Bruker-AXS Crystal Structures Database or obtained from the Crystallography Open Database (COD) or International Crystal Structure Database (ICSD) [33].

X-ray diffraction patterns of the aggregates are presented in Figure 3. The natural aggregate evaluation displays characteristic peaks of crystalline phases of quartz, microcline, muscovite, and fluorite minerals (see Figure 3a), while in the recycled aggregates, nearly the same minerals are found, in addition to calcite (see Figure 3 b). The presence of calcite, i.e., calcium carbonate (CaCO3), evidences the occurrence of cement paste adhered to the recycled aggregate. It is possible to endorse that the recycled aggregate prevails from concrete structures due to the presence of about $12 \%$ of calcite; additionally, a very small content of kaolinite or hydrated aluminum silicate, i.e., a clay mineral, reveals some ceramic contamination. In general, the difference between both aggregates is emphasized by the presence of calcium carbonate. 

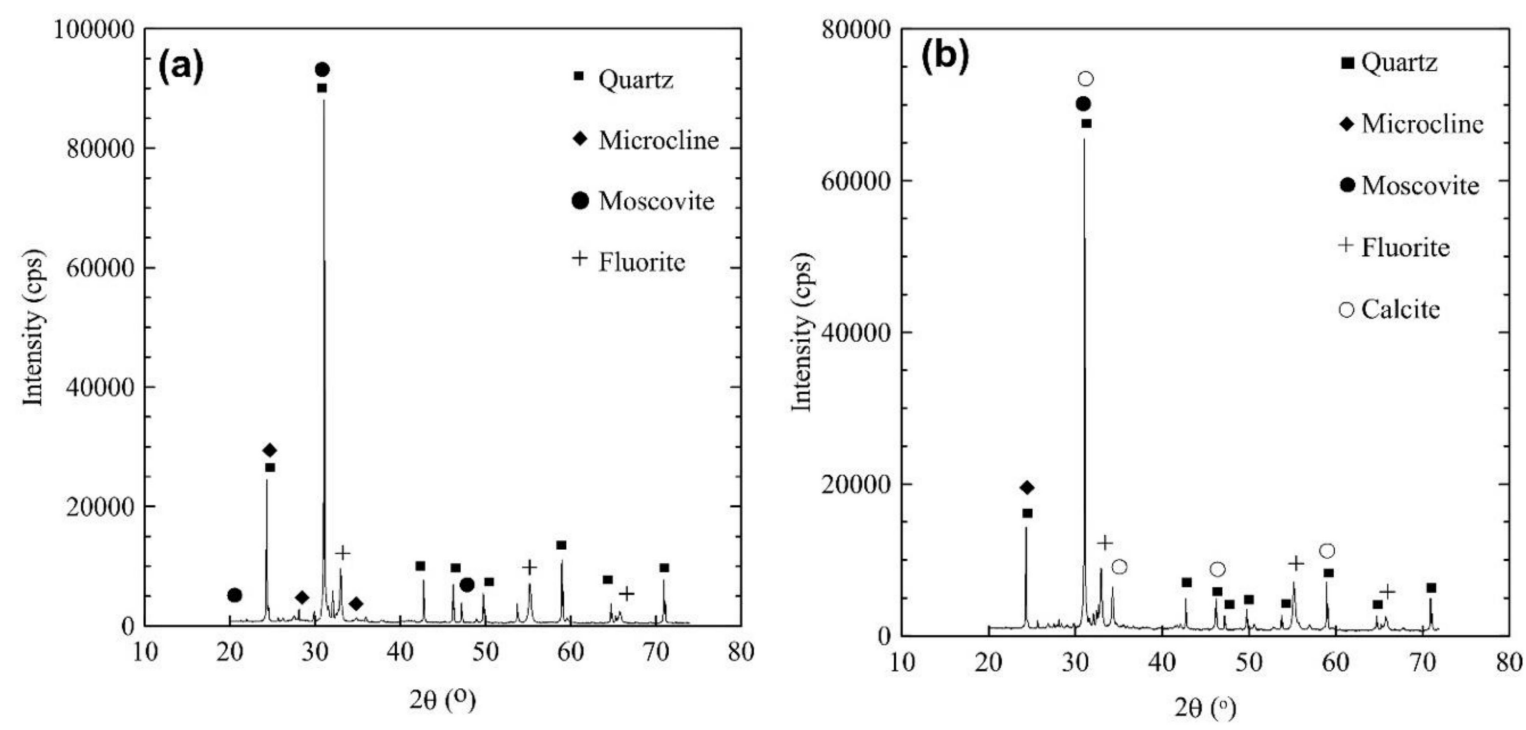

Figure 3. X-ray diffraction pattern of natural (a) and recycled (b) aggregates (Co k $\alpha$ radiation; $35 \mathrm{kV}$ and $40 \mathrm{~mA} ; 0.02^{\circ}$ step size; and $1 \mathrm{~s}$ counting time).

\subsection{Quantification of the Attached Cement Paste}

In this study, the attached cement material was quantified by a chemical attack with hydrochloric acid $(\mathrm{HCl})[34,35]$, which lies on the dissolution of the cement paste when immersing the recycled aggregate in an $\mathrm{HCl}$ solution.

The chemical attack was performed according to Braymand et al. [34] using a 30\% concentrated $\mathrm{HCl}$ solution. First, three aggregate samples of approximately $100 \mathrm{~g}$ were oven-dried at $60 \pm 5{ }^{\circ} \mathrm{C}$ until reaching stable mass, i.e., the initial mass $\left(m_{i}\right)$ recorded. Then, they are immersed in the acidic solution for $24 \mathrm{~h}$, which is sufficient to dissolute the cement matrix. In sequence, the samples are neutralized by water rinse in a $150-\mu \mathrm{m}$ sieve, followed again by the oven drying process. Then, the final mass after attack $\left(m_{f}\right)$ is recorded. Finally, the attached paste $\left(A_{P}\right)$ is the difference between the sample weight after and before the attack as follows.

$$
A_{P}=\frac{m_{i}-m_{f}}{m_{i}}
$$

The amount of attached Portland cement paste determined by the chemical attack is about $43 \%$. It is commonsensical with the previous XRD and SEM analyses that qualitatively display the presence of the attached paste. In principle, it seems more consistent with the 2D image analysis of the SEM pictures than with the Rietvel refinement of the XRD data. Note, however, that the Rietveld method quantifies only the crystalline phases (i.e., underestimating the total quantity), which lies in this considerable difference in quantification between the calcite and the attached paste by chemical attack. Overall, this high percentage of the attached paste covering the (original) aggregate particle explains the raised absorption ratio and low-density properties of the recycled material.

\subsection{Mixture Proportions, Production, and Characterization of the Mortars}

One reference mixture containing $100 \%$ natural aggregates is designed for 28 days compressive strength of around $45 \mathrm{MPa}$. Then, limiting the cement consumption to $750 \mathrm{~kg} / \mathrm{m}^{3}$ and keeping the water-to-cement $(w / c)$ ratio to 0.45 , three different aggregates substitution rates (in volume) are defined to 15,25 , and $50 \%$. Thereby, only the proportion of aggregates (natural and recycled) changed between the four mortars: REF, M15, M25, and M50, respectively.

It is worth noting the difference between the water absorption capacities of each aggregate type used herein. The recycled one absorbs about 4.5 times more water than the natural aggregate. This fact would directly affect the mixture proportion of the three mortars incorporating it. Because any 
additional water related to its absorption capacity is added in the mortar's composition, the effective $w / c$ - obtained by deducting the water amount corresponding to the absorption capacity of the aggregates (see Table 1)—consequently decreases. Table 2 shows the mortar mixture compositions.

Table 2. Mix design and nomenclature of the studied Portland cement mortars.

\begin{tabular}{ccccccc}
\hline \multirow{2}{*}{ Mixtures } & \multicolumn{7}{c}{ Materials $\left(\mathbf{k g} / \mathbf{m}^{\mathbf{3}}\right)$} \\
\cline { 2 - 7 } & Cement & Natural Aggregate & Recycled Aggregate & Water & $\boldsymbol{w} / \boldsymbol{c}$ & Effective $\boldsymbol{w} / \boldsymbol{c}$ \\
\hline REF & 750.00 & 1150.00 & - & 337.50 & 0.45 & 0.43 \\
M15 & 750.00 & 977.97 & 158.12 & 337.50 & 0.45 & 0.42 \\
M25 & 750.00 & 862.92 & 263.52 & 337.50 & 0.45 & 0.41 \\
M50 & 750.00 & 575.28 & 527.05 & 337.50 & 0.45 & 0.38 \\
\hline
\end{tabular}

This experimental step provides classical fresh mortars' characterization from flow table tests, according to ASTM C230 [36] and vane rheometer yield stress data [7,37]. The mortars' preparation was initiated with manual mixing for $30 \mathrm{~s}$ to homogenize the materials, followed by a planetary mixer stirring at $300 \mathrm{rpm}$ for $120 \mathrm{~s}$. Then, the flow table and rheological tests were performed.

The sought rheological parameter of the fluid, namely yield stress, was determined by a Vane spindle rheometer (Brookfield DV-III Ultra Programmable Rheometer) in $600 \mathrm{~mL}$ of a fresh sample within a beaker vessel. The vane dimensions are $8 \mathrm{~mm}$ diameter and $16 \mathrm{~mm}$ length; about twenty times larger than the maximum aggregate diameter-restricted to $0.425 \mathrm{~mm}$-which is necessary to limit disorders in the sample during probe insertion and to define the sheared surface [7]. The loading procedure is adapted from $[7,38]$ and consists of manually placing the fresh sample spading three equal layers $(\approx 200 \mathrm{~mL}$ ) of it to fill the measurement vessel before starting the shearing history. Then, the vane device is inserted to perform shearing, at a given resting time, and an imposed slow angular velocity of $0.1 \mathrm{rpm}$, i.e., rotational speed, as suggested in rheology studies on cementitious materials [7,37-39]. The experiments are performed in laboratory conditions at $21 \pm 2{ }^{\circ} \mathrm{C}$ room temperature, and the data are recorded every $5 \mathrm{~s}$. The static yield stress measures correspond to the maximum shear stress achieved, i.e., at maximum torque. Results are expressed as an average of three samples for each mortar's composition.

Compressive strength experiments are performed in cylindrical specimens of $50 \mathrm{~mm}$ diameter and $100 \mathrm{~mm}$ height at 7 and 28 days. The specimens are cast remaining in a closed container during the first $24 \mathrm{~h}$ to prevent water loss. Then, the specimens remain inside a moist chamber until they reach the age established for the experiment. The experiments are carried out in a servo-hydraulic machine (Shimadzu model UH-F1000kNI) with displacement control at a loading rate of $0.1 \mathrm{~mm} / \mathrm{min}$. Results are expressed as an average of three specimens to determine the mortars' compressive strength (fc) and Young's modulus (E). The latter is recorded considering the axial stress-to-strain ratio obtained within the linear regime. Statistical analyses of the experimental results are performed using analysis of variance to assess significant differences between mortars, which is considered with the probability $p \leq 0.05$.

\section{Life Cycle Impact Assessment}

\subsection{Definition of Goal, Scope, and Functional Unit}

This LCA study aims to evaluate the environmental performance of the studied mortars presented in Table 2. It determines if the replacement of natural by recycled aggregate is a reliable choice in terms of minimizing negative impacts on the environment, considering which aspects are significantly constrained by the recycled aggregates.

The scope of this study is classified as cradle-to-gate since we evaluated the following life cycle stages: (A1) raw materials extraction, (A2) transportation, and (A3) mortars production, according to the recommendations of [40]. The avoided impacts (D) due to the use of recycled aggregates are also 
accounted for. The LCA has been performed with the software SimaPro 8.3. The functional unit (FU) chosen is one $\mathrm{m}^{3}$ of mortar developed and tested in the laboratory. Figure 4 displays the scope and system boundaries for the processing of recycled aggregates from CDW.

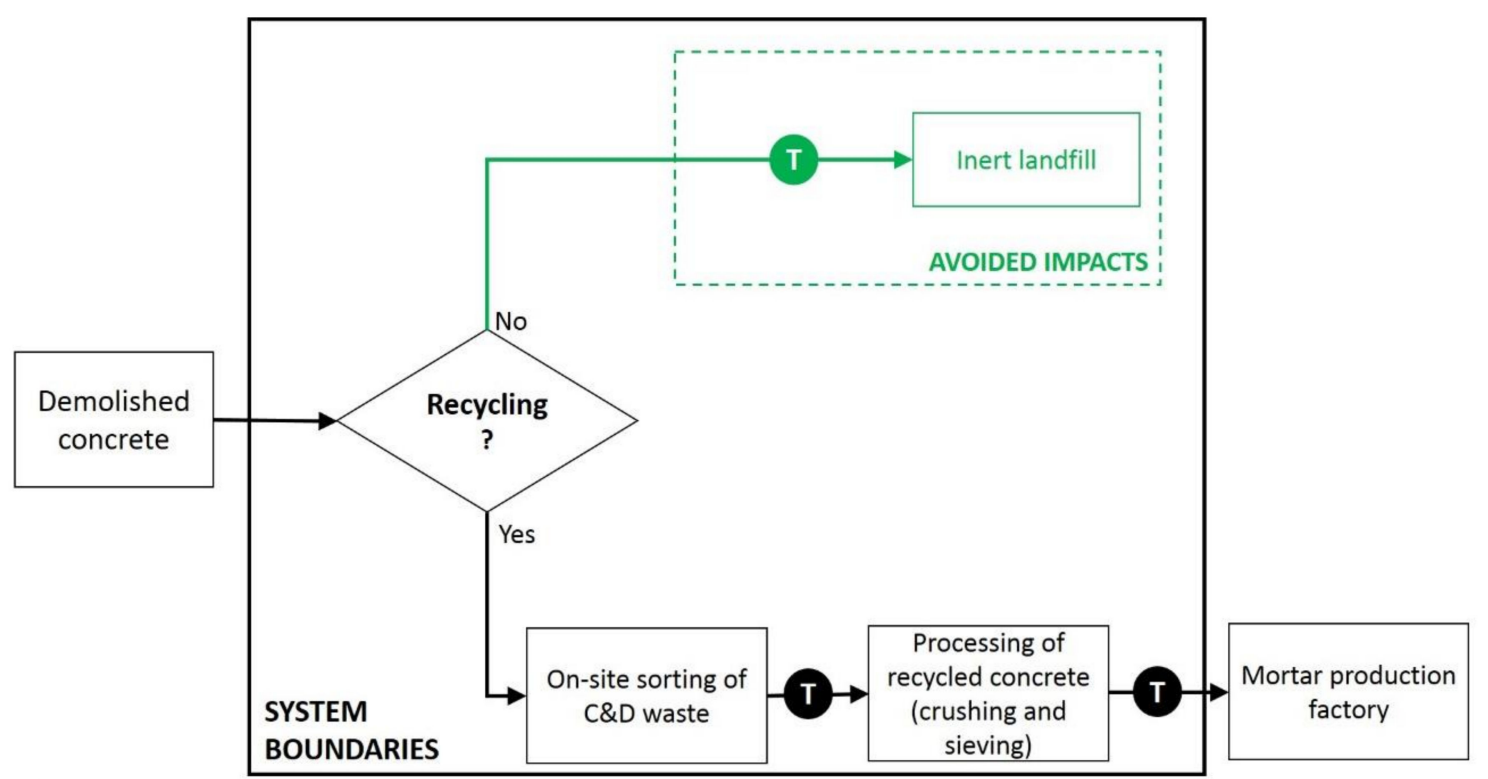

T Transport

Figure 4. System boundaries and processing of the recycled aggregates from construction and demolition waste, including the avoided impacts.

\subsection{Life Cycle Inventory}

For the Life Cycle Inventory (LCI), data from the laboratory (primary), Ecoinvent v. 3.3, and literature were used, adapted to the Brazilian context. Additional information given as Supplementary Material displays all the processes and data used.

\subsection{Avoided Impacts}

The avoided impacts related to the transporting and landfill disposal of CDW were accounted for (green stages of Figure 4) based on Hossain et al. [41]. Furthermore, the avoided impacts associated with the natural aggregates (natural sand) production were also accounted for. Both types of avoided impacts are described in module D, according to EN 15978:2011 [40].

\subsection{Life Cycle Impact Assessment}

The CML method and the categories recommended by EN 15978:2011 [40] were employed for the Life Cycle Impact Assessment (LCIA). The categories presented in Table 3 were evaluated.

Table 3. Environmental categories evaluated in Life Cycle Impact Assessment (LCIA).

\begin{tabular}{cc}
\hline Categories & Unit \\
\hline Abiotic Resource Depletion Potential for nonfossil resources-ADP-n & $\mathrm{kg} \mathrm{Sb}-\mathrm{Eq}$ \\
Abiotic Resource Depletion Potential for fossil resources-ADP-f & $\mathrm{MJ}-\mathrm{ultimate} \mathrm{base}$ \\
Global Warming Potential for a 100-year time frame-GWP100 & $\mathrm{kg} \mathrm{CO}_{2}-\mathrm{Eq}$ \\
Depletion Potential of the Ozone Layer-ODP & $\mathrm{kg} \mathrm{CFC-11-Eq}$ \\
Formation Potential of Tropospheric Ozone-POCP & $\mathrm{kg} \mathrm{C}_{2} \mathrm{H}_{4}-\mathrm{Eq}$ \\
Acidification Potential-AP & $\mathrm{kg} \mathrm{SO}_{2}-\mathrm{Eq}$ \\
Eutrophication Potential-EP & $\left.\mathrm{kg} \mathrm{(PO}_{4}\right)^{3-}-\mathrm{Eq}$ \\
\hline
\end{tabular}




\subsection{Sensitivity Analysis}

The sensitivity analyses performed herein verify how the main system boundaries and assumptions influence the LCA results, according to the parameters presented in Table 4, followed from previous studies [42-44].

Table 4. Parameters evaluated in sensitivity analysis.

\begin{tabular}{cl}
\hline \multicolumn{1}{c}{ Aspects } & \multicolumn{1}{c}{ Description } \\
\hline Portland cement types & $\begin{array}{l}\text { Two cement types, an alternative one frequently available in the Brazilian } \\
\text { market, with mineral additions of filler and blast furnace slag, namely CPII-E40 } \\
\text { (around 70\% of clinker) and the CPV adopted during the experimental } \\
\text { investigation. This choice is valid since cement is the material that most } \\
\text { contributes to concrete and mortar's environmental impacts [42]. }\end{array}$ \\
\hline Recycling plant type & $\begin{array}{l}\text { Two different recycling plants, which are powered by electricity or diesel, } \\
\text { as previously described by [43]. }\end{array}$ \\
\hline Transport distances & $\begin{array}{l}\text { Transportation distances of the recycled aggregates; performed for the reference } \\
\text { and M50 mortars (with the highest content of recycled aggregates). } \\
\text { This evaluation provides information on how far the recycled aggregate can be } \\
\text { transported without compromising its environmental performance when } \\
\text { compared to the reference mortar [44]. }\end{array}$ \\
\hline
\end{tabular}

\subsection{Environmental Performance Indicator}

An environmental-mechanical performance indicator (in environmental impact unit $/ \mathrm{m}^{3}$. MPa), e.g., for GWP100 is presented in $\mathrm{kg} \mathrm{CO} 2-\mathrm{Eq} / \mathrm{m}^{3}$. $\mathrm{MPa}$, was adopted to validate the differences between the compressive strength of the mortars relating it to the environmental categories. This approach was successfully applied in previous studies [42,45].

\section{Results}

\subsection{Effect of Recycled Particles on the Yield Stress Measurements}

Figure 5a displays typical shear stress vs. time curves-based on Tm-t profiles extracted from the vane experiments-for the plain and recycled mortars studied herein. For all loaded mixtures, the shear stress increases nearly linear up to the complete failure of bonds independent of the yield stress value achieved. It occurs at approximately $50 \mathrm{~s}$, except for the mortar containing $50 \%$ of recycled sand that reaches its maximum peak value at about $90 \mathrm{~s}$. Then, the maintenance of the experiment originates stress results to fall towards a steady-state zone, where they oscillate $\pm 0.1 \mathrm{kPa}$ up to around $160 \mathrm{~s}$. Overall, the calculated yield stresses increase with the aggregate substitution rate. This behavior is presented in Figure $5 \mathrm{~b}$ concerning the effective $w / c$ ratio. In particular, substituting 25 and $50 \%$ of natural by recycled sand increases $\tau_{0}$ about 22 and $45 \%$, respectively.

The calculated yield stress and the slump flow results are confronted in Figure 6. We observe the spreading flow values decreasing as the yield stress increases. This is expected since the replacement of natural by recycled aggregates was performed without compensating water. This means less free water remaining in the final mixture. In addition, the water demand of the higher porosity and absorption ratio of the recycled aggregates grows as the substitution rate of natural by recycled aggregates increases. These results are in accordance with previous studies (see, e.g., Duan et al. [11] and Jiang et al. [13]). 


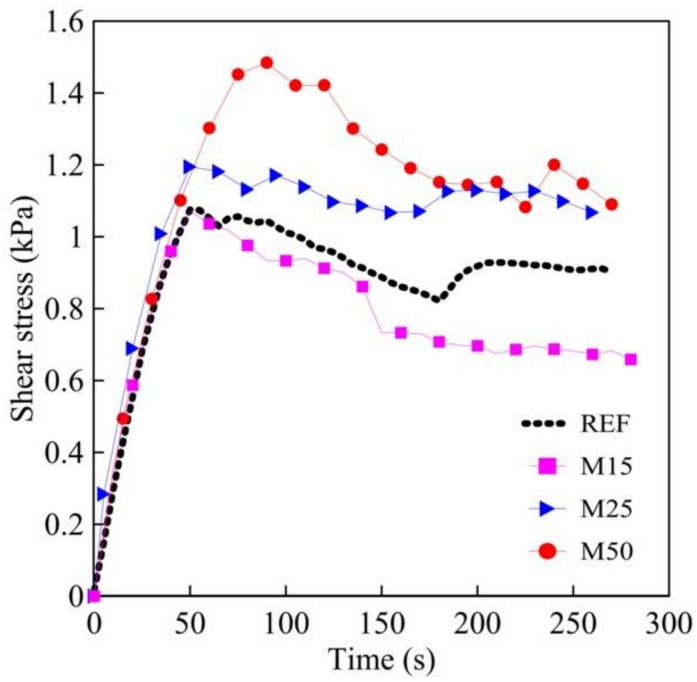

(a)

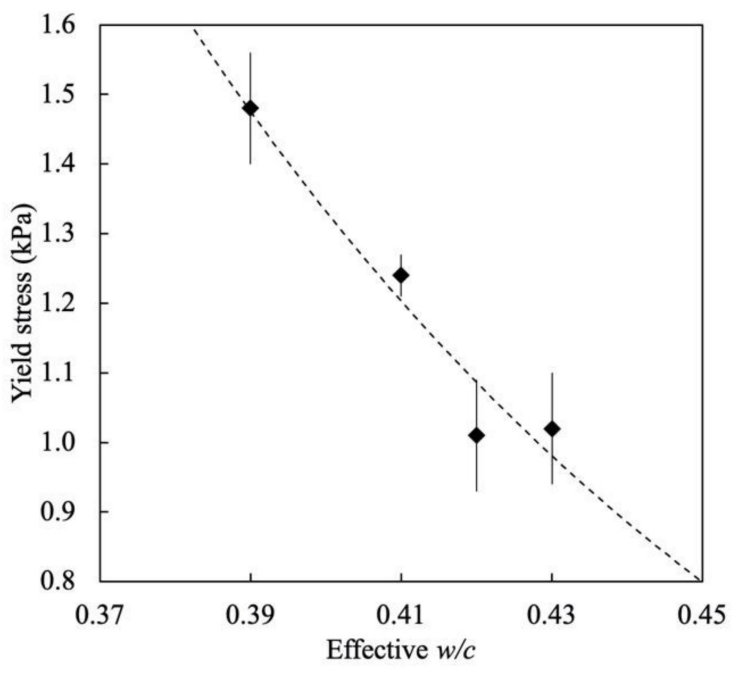

(b)

Figure 5. (a) typical shear stress vs. time curves of the four mortars obtained when shearing is applied at a low rotational velocity of $0.1 \mathrm{rpm}$; (b) the variations of yield stress responses with the effective $w / c$ ratio for all mortars. The dashed line corresponds to an exponential approximation $\left(\mathrm{R}^{2}=0.92\right)$, where $\tau_{1}=79.3$ and $w_{0}=10.2$ are fitting parameters.

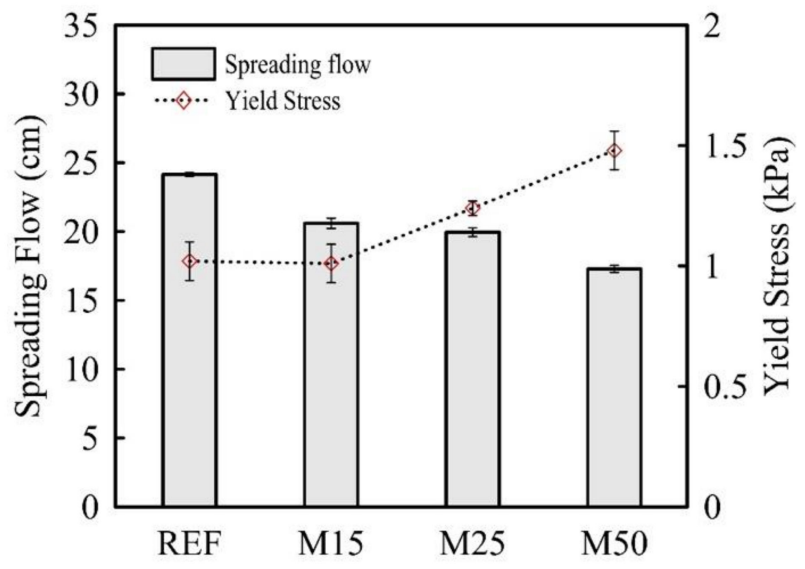

Figure 6. Comparison of spreading flow and yield stress values for all mixtures.

\subsection{Compressive Strength Behavior}

Figure 7 displays typical stress-strain curves for the mortars tested at 28 days. The linear elastic behavior remains nearly the same-ranging from 40 to $45 \%$ of the peak stress-for the reference mixture and the mortars M15 and M25. In contrast, the results of M50 show a linear elastic branch moving upwards to $52 \%$ of the total stress, although the statistical analysis confirms the absence of significant differences between the Young's Modulus of all mortars. Interestingly, the inclusion of lightweight aggregates supposes to increase the linearity of the stress-strain curve since its Young's modulus is lower than that of the rock aggregate and analogous to that of the mortar [46]. Strictly speaking, the presence of the attached cement paste covering the regular rock aggregate promotes rough and porous surface features, which seems to lightweight aggregates superficial characteristics. Nevertheless, let us emphasize that both the recycled concrete aggregate and the resulting mortars designed herein have different properties than regular lightweight aggregates and mortars themselves. 


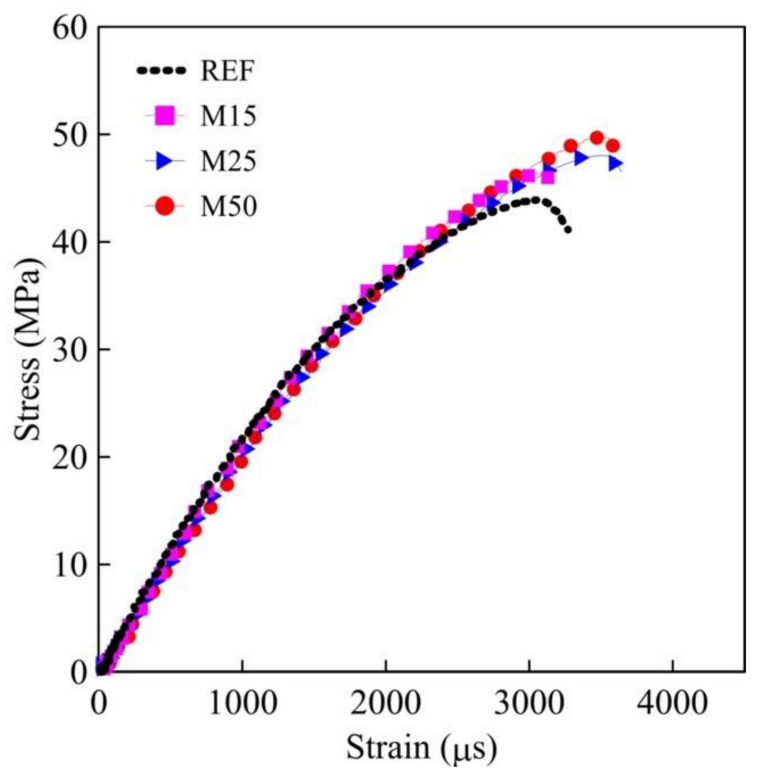

Figure 7. Typical compressive stress-strain curves at 28 days of all mixtures with different substitution rates.

Figure 8 presents the mortars' 7- and 28-day strength evolution as a function of the effective $w / c$ ratio (see Table 3). As expected, an evolution of the compressive strength from 7 to 28 days occurs for all mixtures. In particular, we observe that increasing the amount of recycled aggregate increases the compressive strength of mortars, in opposition to other studies $[47,48]$. For instance, the mixture with the lower effective $w / c$ ratio (M50) presents an average compressive strength of about $10 \mathrm{MPa}$ higher than that of highest $w / c$ (REF) at 7 days and around 7 MPa higher at 28 days. On the other hand, when substituting $15 \%$ of the natural by recycled aggregates, i.e., modifying the effective $w / c$ ratio only at 0.01 , the mortar M15 reached about half of the total increment achieved by the M50 (e.g., 5 and $3 \mathrm{MPa}$ at 7 and 28 days, respectively). Overall, these strength improvements in comparison to REF represent 6, 13, and 15\% for M15, M25, and M50, respectively, at 28 days. Let us note that this strength performance may be related to different mechanisms, such as the aggregate surface roughness and the effective $w / c$ ratio that are going to be discussed in the next section.

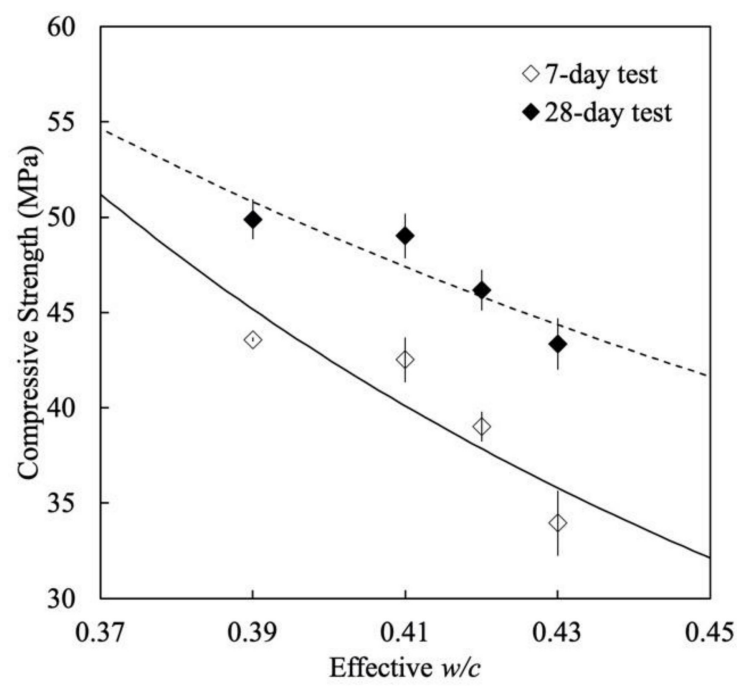

Figure 8. The 7- and 28-day compressive strength as a function of the effective $w / c$ ratio of all mortars. The straight $\left(R^{2}=0.78\right)$ and dashed $\left(R^{2}=0.83\right)$ curves correspond to the approximation of Equation $(2)$, where $\sigma_{0}=4.8$ and $\gamma=-2.4$ are the parameters at 7 days, while at 28 days $\sigma_{0}=13.7$ and $\gamma=-1.4$. 


\subsection{Environmental Performance}

Figures 9 and 10 show the normalized environmental impacts of the evaluated mixtures considering different scenarios: first, CPV-ARI (cement of $90 \%$ clinker content) coupled to a diesel-fueled recycling plant; and second, the CPII-E40 (about 70\% clinker content) with an electricity recycling plant. The detailed information of the LCA results is given as Supplementary Material.

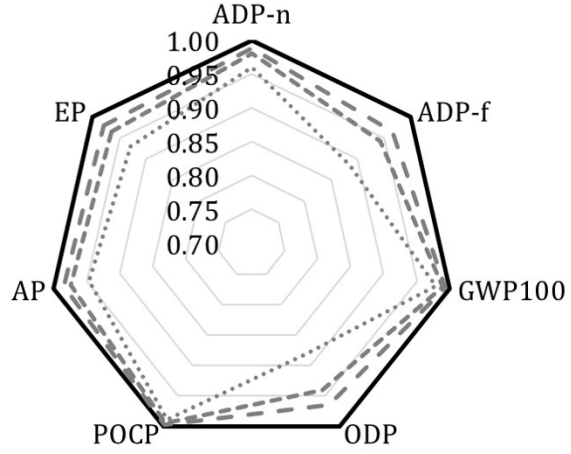

(a)

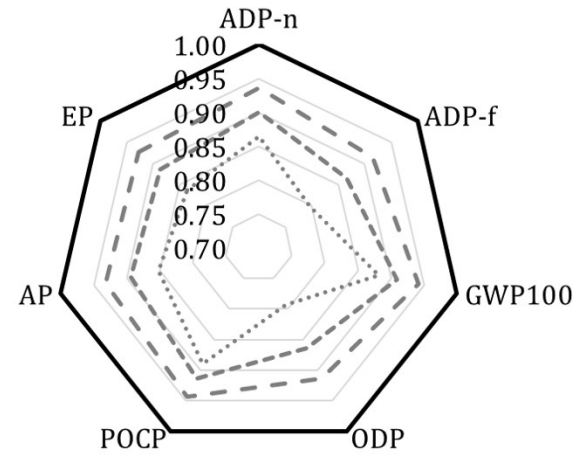

(b)

$$
\text { - REF - - M15 --- M25 …...M50 }
$$

Figure 9. Normalized indicators in a radar diagram for the reference of mortar considering CPV-ARI and a diesel-fueled recycling plant. (a) Impacts per $\mathrm{m}^{3}$. (b) Impacts per $\mathrm{m}^{3}$. MPa. ADP-n-Abiotic Resource Depletion Potential for Nonfossil resources ADP-f-Abiotic Resource Depletion Potential for fossil resources. GWP100-Global Warming Potential for a 100-year time frame. ODP-Depletion Potential of the Ozone Layer. POCP-Formation Potential of Tropospheric Ozone. AP-Acidification Potential. EP-Eutrophication Potential.

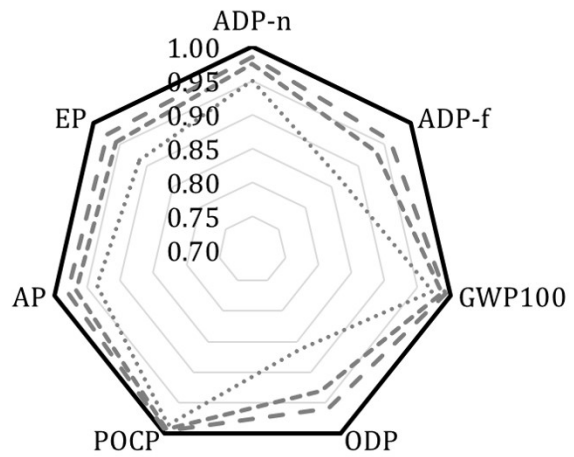

(a)

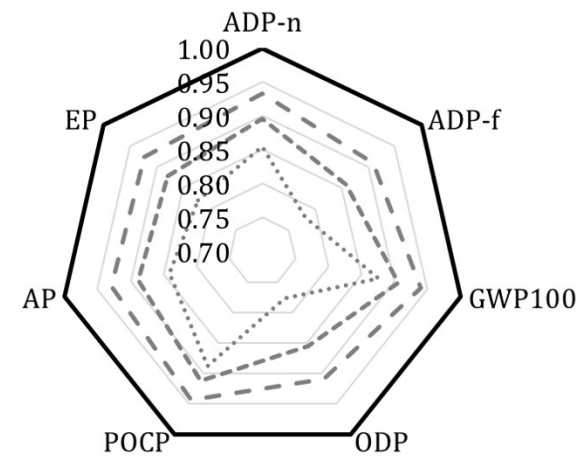

(b)

$$
\text { - REF - - M15 --- M25 …...M50 }
$$

Figure 10. Normalized indicators in a radar diagram for the reference of mortars with cement CPII-E40 and an electricity recycling plant. (a) Impacts per $\mathrm{m}^{3}$. (b) Impacts per $\mathrm{m}^{3}$. MPa. ADP-n-Abiotic Resource Depletion Potential for Nonfossil resources ADP-f-Abiotic Resource Depletion Potential for fossil resources. GWP100-Global Warming Potential for a 100-year time frame. ODP-Depletion Potential of the Ozone Layer. POCP-Formation Potential of Tropospheric Ozone. AP-Acidification Potential. EP-Eutrophication Potential.

Increasing the substitution rate of aggregates improves the environmental performance at all environmental categories. The most considerable difference between M50 and the reference mixture occurred for the ODP and ADP-ff categories, reaching 14 and 13\%, respectively, for the best scenario (smallest environmental impact for recycled aggregate treatment and highest avoided 
impact, considering the CPII-E40 cement). The differences also increase when normalizing the data by the compressive strength (Figures $9 \mathrm{~b}$ and $10 \mathrm{~b}$ ). This is related to the satisfactory environmental and mechanical performance of mortars with recycled aggregates that increase $22 \%$ for both environmental categories.

It is worth noting that the source for powering the recycling process (diesel or electricity) showed irrelevant differences (less than 1\% for all the mentioned categories) since the contribution of this process is insignificant. Concerning the avoided impacts, the inert landfill and solid waste transportation to landfills were the meaningful aspects for most of the categories. These results pointed out the importance of the logistics aspects in terms of recycling.

Moreover, the differences between the mixtures were trivial since the Portland cement is the main contributor for most of the environmental categories [24], particularly when adopting the attributional LCA. Indeed, the categories have their results smoothed when simulating mixtures with cement CPII-E40 instead of CPV-ARI, as the first one has a smaller impact.

The results of the sensitivity analysis in terms of the maximum supply distance of recycled aggregate (Figures 11 and 12) present values ranging from $200 \mathrm{~km}$ (best scenario) to $700 \mathrm{~km}$ (worst scenario) for most environmental impact categories, excluding only ADP-n. In particular, its maximum distances are even higher-from 600 to $850 \mathrm{~km}$ - as a result of the slight contribution of the diesel consumption in transportation for the ADP-n. Nevertheless, since diesel is a fossil fuel, it has also a noteworthy effect on ADP-f and ODP, which is in accordance with Pradhan et al. [44]. This analysis has been considered an efficient tool in the design guidelines for the environmental availability of recycled aggregates in recent LCA studies [24,49].
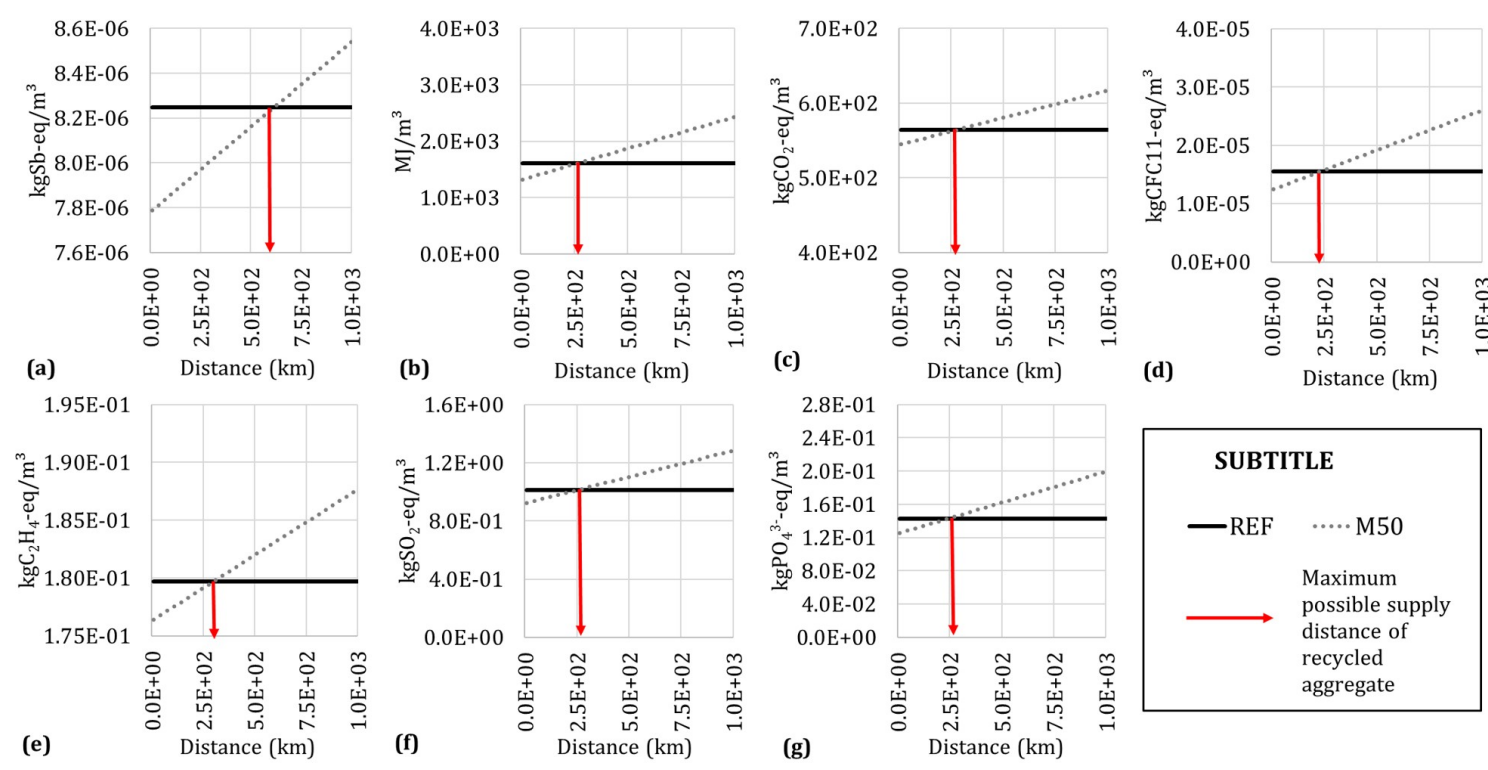

Figure 11. The influence of the delivery distance of the recycled aggregate considering the cement CPII and recycling with electricity for the best scenario (minimum transportation distances). (a) ADP-n-Abiotic Resource Depletion Potential for Nonfossil resources. (b) ADP-f-Abiotic Resource Depletion Potential for fossil resources. (c) GWP100-Global Warming Potential for a 100-year time frame. (d) ODP-Depletion Potential of the Ozone Layer. (e) POCP-Formation Potential of Tropospheric Ozone. (f) AP_Acidification Potential. (g) EP-Eutrophication Potential. 

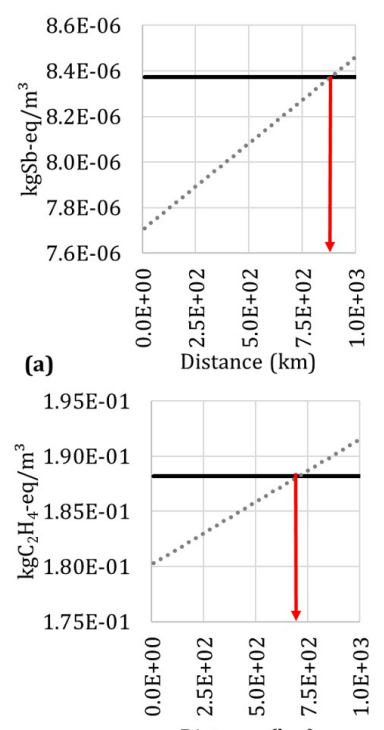

(e)

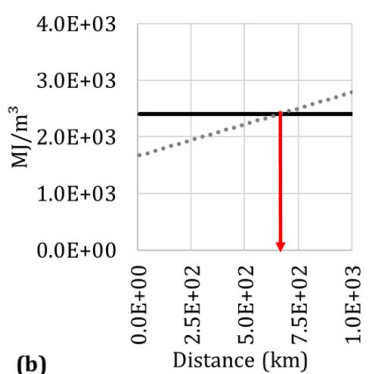

(b)

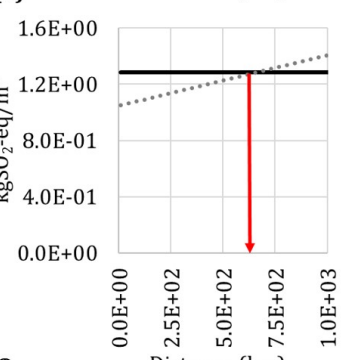

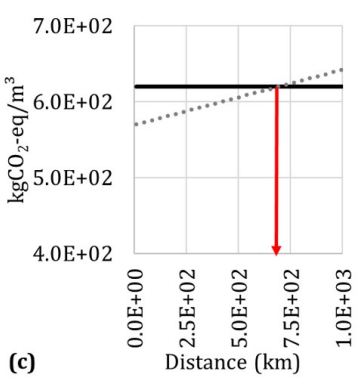

(c)

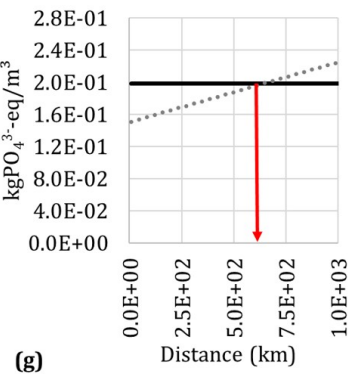

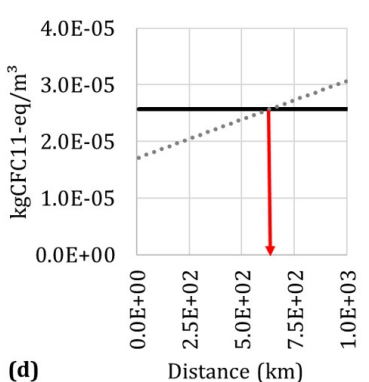

(d)

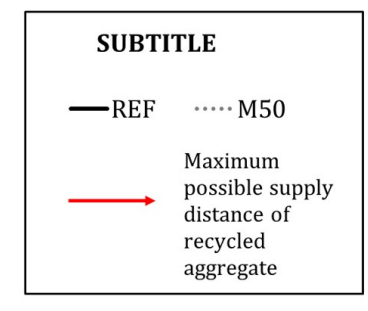

Figure 12. The influence of the delivery distance of the recycled aggregate considering the cement CPII and recycling with electricity for the worst scenario (maximum transportation distances). (a) ADP-n-Abiotic Resource Depletion Potential for Nonfossil resources. (b) ADP-f-Abiotic Resource Depletion Potential for fossil resources. (c) GWP100-Global Warming Potential for a 100-year time frame. (d) ODP-Depletion Potential of the Ozone Layer. (e) POCP-Formation Potential of Tropospheric Ozone. (f) AP-Acidification Potential. (g) EP-Eutrophication Potential.

\section{Discussion}

Several overlapping effects may lead to the strength improvements observed herein when increasing the recycled aggregate volume. For instance, the aggregates' surface roughness plays an important role in the compressive strength of mortars [50], such as it happens when comparing the recycled aggregates porous surface (i.e., greater surface area) to the natural ones. Furthermore, the grip between the paste and the aggregate at the interfacial transition zone will be improved when considering a rough aggregate, thereby leading to an improved compressive strength [51].

As one of the objectives of the study is to evaluate the mortars' properties after introducing recycled aggregates that absorb 4.5 times more water in their composition, no water compensation is performed, allowing us to understand the straight effect of this inclusion on the mortar's rheological behavior. Indeed, the mortars with recycled aggregates have less free water available, since the water is absorbed by the recycled aggregates. This leads to the reduction of the effective $w / c$ ratio, determined by the relationship of the new water amount (after reducing the amount absorbed by the aggregates) and cement. Figure $5 b$ displays that the decreasing effective $w / c$ increases the yield stress and thus is correlated to the $w / c$ ratio variations by an exponential function $\tau_{0}=\tau_{1} \times e^{\left(w_{0}(w / c)\right)}$, where $\tau_{1}=79.3$ and $w_{0}=10.2$ are fitting parameters. This evidences the profound effect of the water absorption capacity of the recycled aggregate on the fresh state behavior of mortars.

The above discussion relates to the understanding of the expected effect of the simple substitution of natural by recycled aggregate, which presents a relatively higher harshness, increasing the friction between the particles [52] and, consequently, improvement occurs in the mechanical behavior thereof. As can be seen in Figure 8, the compressive strength of the mortars is inversely proportional to the $w / c$ ratio following a power law as follows

$$
\sigma=\sigma_{0}\left(\frac{w}{c}\right)^{\gamma}
$$

as classically designed in concretes, where $\sigma_{0}$ and $\gamma$ are fitting parameters. Interestingly, this approximation works at 7 days as well as at 28 days, confirming the presented trend and the expected effect of $w / c$ on the compressive strength of the material. 
Overall, the above discussion shows that the variations on the recycled concrete microaggregate ratio in the mixture proportioning of Portland cement mortars affect their rheological and mechanical performances. The general explanation for these changes is mainly related to water absorbed by the recycled microaggregates that decreases the $w / c$ ratio of the mortars containing them. Another route is considering to correct the water absorption capacity of the aggregate in the mix-design [47], which led to the less expressive influence of the recycled microparticles on the mortars' properties. This particular point would deserve further work.

Therefore, considering the wide range of possibilities to the mortars' practical applications (rendering, plastering, structural, etc.), the approach presented here can be an interesting option to design cement mortar, giving a suitable destination to the concrete residue, maintaining (or even enriching) the strength performance of the material, and varying with its workability. This fact validates the adoption of recycled concrete microaggregate without correcting its absorption capacity, although a few more benefits are found in terms of environmental impact.

The evaluation of different scenarios in LCA (best, intermediate, and worst) is important when avoided impacts are accounted for due to high end-of-life uncertainties. For the best case, the avoided impacts resulted in negative impacts. In other words, increasing recycled aggregates replacement rates in mortars sharply decrease the results of some environmental categories as ODP and ADP-f. These different scenarios played an important role in the sensitivity analysis related to the maximum supply distance of recycled aggregate (see Figures 11 and 12). We observed that the allowed distances roughly triplicate, which, in practice, directly impacts the feasibility of using recycled aggregates. The values ranging from 200 to $300 \mathrm{~km}$ for the best scenario were in the same range as those found in previous studies (see Pradhan et al. [44] and Hossain et al. [41]). Even studies for countries of small territory size, where transportation distances are shorter (typically $50 \mathrm{~km}$ ), have shown that the environmental impact of the aggregate replacement is still important (see Marinković et al. [53] and Knoeri et al. [54]). Hence, transportation plays an important role in the topic and might stand as a barrier to use recycled aggregates in some cases, particularly within large territory countries.

When considering time-consuming transportation distances of the other raw materials (e.g., cement and natural sand), the results show favorable prospects for using recycled aggregates from remote locations. In other words, the farther the source location of the raw materials, the steadier the scenario to RA acceptance. From a logistics point of view, this is a very advantageous feature.

Finally, the association between mechanical and environmental performance data, in a quantitative fashion, revealed the potentials of recycled aggregates in a micrometer scale to replace natural river sand in cement-based materials. In particular, to prevent the discarding of particles that represent usually unworkable solid waste fractions.

\section{Conclusions}

This study demonstrated the environmental performance of cement-based mortars containing recycled concrete particles from the demolition of a hospital building. LCA analysis was performed in addition to rheological and mechanical experiments that were discussed independently. Based on the results of the present research, it can be concluded that the mass replacement content of natural by recycled micro aggregates induces less workable yet more resistant and efficient mixtures.

The environmental performance assessment indicated that the mortars with the highest amount of recycled micro aggregate were less detrimental to the environment, especially for the ozone layer depletion potential and abiotic resource depletion potential categories. In this study, these environmental advantages were heavily influenced by the long transportation distances (related to all materials' origins) that went from 200 to $700 \mathrm{~km}$, for most categories.

Finally, the noteworthy association between mechanical and environmental performances validated the possibility of developing eco-efficient materials using micrometer-scale recycled particles that are usually discarded. 
The authors consider that this study provides insights for dealing with problems of such magnitude as the building demolition and the waste generated, which is becoming increasingly common worldwide; thus, assisting the implementation of a Circular Economy in the construction industry.

Supplementary Materials: The following are available online at http://www.mdpi.com/2071-1050/12/21/8945/s1, Table S1: Inputs used for aggregates modeling, Table S2: Distance of transportation considered in the modeling, Table S3: Ecoinvent v. 3.3 datasets used in the LCA modelling, Table S4: Mortar REF_LCA results, Table S5: Mortar M15-LCA results for diesel recycling plant, Table S6: Mortar M15-LCA results for electricity recycling plant, Table S7: Mortar M25-LCA results for diesel recycling plant, Table S8: Mortar M25-LCA results for electricity recycling plant, Table S9: Mortar M50_LCA results for diesel recycling plant, Table S10: Mortar M50-LCA results for electricity recycling plant, Table S11: Natural and recycled aggregates-LCA results, Table S12: Natural aggregate—Detailed LCA results, Table S13: Recycled aggregate-diesel recycling plant—Detailed LCA results, Table S14: Recycled aggregate-electricity recycling plant-Detailed LCA results.

Author Contributions: Conceptualization, T.M.G. and R.D.T.F.; methodology, T.M.G and L.R.C.; software, T.M.G. and L.R.C.; validation, T.M.G.; formal analysis, L.R.C. and N.R.J.; investigation, N.R.J.; resources, T.M.G. and R.D.T.F.; data curation, T.M.G.; writing—original draft preparation, T.M.G., N.R.J., and L.R.C.; writing一review and editing, T.M.G. and L.R.C.; visualization, T.M.G. and L.R.C.; supervision, R.D.T.F.; project administration, T.M.G. and R.D.T.F.; funding acquisition, R.D.T.F. All authors have read and agreed to the published version of the manuscript.

Funding: This study was financed in part by the Coordenação de Aperfeiçoamento de Pessoal de Nível Superior-Brasil (CAPES)_Finance Code 001; by Conselho Nacional de Desenvolvimento Científico e Tecnológico (CNPq); and by the Fundação Carlos Chagas Filho de Amparo à Pesquisa do Estado do Rio de Janeiro (FAPERJ).

Acknowledgments: It is a pleasure to acknowledge the financial support for this investigation provided by the Brazilian agencies CAPES, CNPq, and FAPERJ. The authors also thank Dr. Marco Pepe for useful discussions.

Conflicts of Interest: The authors declare no conflict of interest.

\section{References}

1. Duan, H.; Miller, T.R.; Liu, G.; Tam, V.W.Y. Construction debris becomes growing concerns of growing cities. Waste Manag. 2019, 83, 1-5. [CrossRef] [PubMed]

2. Schoon, J.; De Buysser, K.; Van Driessche, I.; De Belie, N. Fines extracted from recycled concrete as alternative raw material for Portland cement clinker production. Cem. Concr. Compos. 2015, 58, 70-80. [CrossRef]

3. Rangel, C.S.; Toledo Filho, R.D.; Amario, M.; Pepe, M.; de Castro Polisseni, G.; Puente de Andrade, G. Generalized quality control parameter for heterogenous recycled concrete aggregates: A pilot scale case study. J. Clean. Prod. 2019, 208, 589-601. [CrossRef]

4. Farinha, C.; de Brito, J.; Veiga, R. Incorporation of fine sanitary ware aggregates in coating mortars. Constr. Build. Mater. 2015, 83, 194-206. [CrossRef]

5. Bogas, J.A.; Carriço, A.; Pereira, M.F.C. Mechanical characterization of thermal activated low-carbon recycled cement mortars. J. Clean. Prod. 2019, 218, 377-389. [CrossRef]

6. Ferreira, J.C.; Grabois, T.M.; Calcado, G.C.S.; Filho, R.D.T. Stress-Strain Behavior of Mortar Mixtures Containing Construction and Demolition Waste as Fine Aggregate. Key Eng. Mater. 2014, 634, 300-306. [CrossRef]

7. Bauer, E.; de Sousa, J.G.G.; Guimarães, E.A.; Silva, F.G.S. Study of the laboratory Vane test on mortars. Build. Environ. 2007, 42, 86-92. [CrossRef]

8. Silva, R.V.; De Brito, J.; Dhir, R.K. Performance of cementitious renderings and masonry mortars containing recycled aggregates from construction and demolition wastes. Constr. Build. Mater. 2016, 105, 400-415. [CrossRef]

9. Le, T.; Rémond, S.; Le Saout, G.; Garcia-Diaz, E. Fresh behavior of mortar based on recycled sand-Influence of moisture condition. Constr. Build. Mater. 2016, 106, 35-42. [CrossRef]

10. Zhao, Z.; Remond, S.; Damidot, D.; Xu, W. Influence of fine recycled concrete aggregates on the properties of mortars. Constr. Build. Mater. 2015, 81, 179-186. [CrossRef]

11. Duan, Z.; Hou, S.; Xiao, J.; Singh, A. Rheological properties of mortar containing recycled powders from construction and demolition wastes. Constr. Build. Mater. 2020, 237, 117622. [CrossRef]

12. Lima, P.R.L.; Toledo Filho, R.D.; Gomes, O.D.F.M. Influence of Recycled Aggregate on the Rheological Behavior of Cement Mortar. Key Eng. Mater. 2014, 600, 297-307. [CrossRef] 
13. Jiang, J.; Zhou, W.; Gao, Y.; Wang, L.; Wang, F.; Chu, H.Y.; Xu, G.; Vandevyvere, B.; Sierens, Z.; Li, J. Feasibility of manufacturing ultra-high performance cement-based composites (UHPCCs) with recycled sand: A preliminary study. Waste Manag. 2019, 83, 104-112. [CrossRef] [PubMed]

14. Ministério de Minas e Energia. Areia Industrial Relatório Técnico 44; Ministério de Minas e Energia: Brasília, Brazil, 2010.

15. Fundação João Pinheiro. Déficit Habitacional no Brasil | 2013-2014; Fundação João Pinheiro: Belo Horizonte, Brazil, 2016.

16. Foroutan, M.; Hassan, M.M.; Desrosiers, N.; Rupnow, T. Evaluation of the reuse and recycling of drill cuttings in concrete applications. Constr. Build. Mater. 2018, 164, 400-409. [CrossRef]

17. Ferreira, S.R.; Pepe, M.; Martinelli, E.; de Andrade Silva, F.; Toledo Filho, R.D. Influence of natural fibers characteristics on the interface mechanics with cement based matrices. Compos. Part B Eng. 2018, 140, 183-196. [CrossRef]

18. Fidelis, M.E.A.; Toledo Filho, R.D.; Silva, F.D.A.; Mechtcherine, V.; Butler, M.; Hempel, S. The effect of accelerated aging on the interface of jute textile reinforced concrete. Cem. Concr. Compos. 2016, 74, 7-15. [CrossRef]

19. Wang, X.; Yu, R.; Shui, Z.; Song, Q.; Liu, Z.; Bao, M.; Liu, Z.; Wu, S. Optimized treatment of recycled construction and demolition waste in developing sustainable ultra-high performance concrete. J. Clean. Prod. 2019, 221, 805-816. [CrossRef]

20. Ding, T.; Xiao, J.; Qin, F.; Duan, Z. Mechanical behavior of 3D printed mortar with recycled sand at early ages. Constr. Build. Mater. 2020, 248, 118654. [CrossRef]

21. Wu, H.; Duan, H.; Wang, J.; Wang, T.; Wang, X. Quantification of carbon emission of construction waste by using streamlined LCA: A case study of Shenzhen, China. J. Mater. Cycles Waste Manag. 2015, 17, 637-645. [CrossRef]

22. Umar, U.A.; Shafiq, N.; Malakahmad, A.; Nuruddin, M.F.; Khamidi, M.F. A review on adoption of novel techniques in construction waste management and policy. J. Mater. Cycles Waste Manag. 2017, 19, 1361-1373. [CrossRef]

23. Ghanbari, M.; Abbasi, A.M.; Ravanshadnia, M. Production of natural and recycled aggregates: The environmental impacts of energy consumption and CO2 emissions. J. Mater. Cycles Waste Manag. 2018, 20, 810-822. [CrossRef]

24. Zhang, Y.; Luo, W.; Wang, J.; Wang, Y.; Xu, Y.; Xiao, J. A review of life cycle assessment of recycled aggregate concrete. Constr. Build. Mater. 2019, 209, 115-125. [CrossRef]

25. Barreiros, G.; Akiti, T.; Magalhães, A.C.G.; Nouér, S.A.; Nucci, M.; Magalhaes, A.C.G.; Nouer, S.A.; Nucci, M. Effect of the implosion and demolition of a hospital building on the concentration of fungi in the air. Mycoses 2015, 58, 707-713. [CrossRef] [PubMed]

26. Pepe, M.; Toledo Filho, R.D.; Koenders, E.A.B.; Martinelli, E. Alternative processing procedures for recycled aggregates in structural concrete. Constr. Build. Mater. 2014, 69, 124-132. [CrossRef]

27. Bao, Z.; Lu, W. Developing efficient circularity for construction and demolition waste management in fast emerging economies: Lessons learned from Shenzhen, China. Sci. Total Environ. 2020, 724, 138264. [CrossRef]

28. Associação Brasileira de Normas Técnicas. Portland Cement-Requirements; NBR 16697; ABNT: Rio de Janeiro, Brazil, 2018.

29. Associação Brasileira de Normas Técnicas. Fine Aggregate-Determination of the Bulk Specific Gravity and Apparent Specific Gravity; NBR NM 52; ABNT: Rio de Janeiro, Brazil, 2009.

30. Associação Brasileira de Normas Técnicas. Fine Aggregate-Test Method for Water Absorption; NBR NM 30; ABNT: Rio de Janeiro, Brazil, 2001.

31. Gomes, O.D.F.M.; Lima, P.R.L.; Fontes, A. Morphological Characterization of Natural and Artificial Sands through Image Analysis; Springer: Berlin/Heidelberg, Germany, 2011.

32. The International Centre for Diffraction Data. International Centre for Diffraction Data-PDF4+Relational Powder Diffraction File; ICDD: Newton Square, PA, USA, 2014.

33. Neumann, R.; Avelar, A.N.; Costa, G.M. Refinement of the isomorphic substitutions in goethite and hematite by the Rietveld method, and relevance to bauxite characterization and processing. Miner. Eng. 2014, 55, 80-86. [CrossRef]

34. Braymand, S.; Roux, S.; Fares, H.; Déodonne, K.; Feugeas, F. Separation and Quantification of Attached Mortar in Recycled Concrete Aggregates. Waste Biomass Valorization 2017, 8, 1393-1407. [CrossRef] 
35. Kim, H.S.; Kim, B.; Kim, K.S.; Kim, J.M. Quality improvement of recycled aggregates using the acid treatment method and the strength characteristics of the resulting mortar. J. Mater. Cycles Waste Manag. 2017, 19, 968-976. [CrossRef]

36. ASTM. C230/C230M-14 Standard Specification for Flow Table for Use in Tests of Hydraulic Cement; ASTM: West Conshohocken, PA, USA, 2014.

37. Assaad, J.J.; Harb, J.; Maalouf, Y. Effect of vane configuration on yield stress measurements of cement pastes. J. Nonnewton. Fluid Mech. 2016, 230, 31-42. [CrossRef]

38. Mahaut, F.; Mokéddem, S.; Chateau, X.; Roussel, N.; Ovarlez, G. Effect of coarse particle volume fraction on the yield stress and thixotropy of cementitious materials. Cem. Concr. Res. 2008, 38, 1276-1285. [CrossRef]

39. Cordeiro, G.C.; de Alvarenga, L.M.S.C.; Rocha, C.A.A. Rheological and mechanical properties of concrete containing crushed granite fine aggregate. Constr. Build. Mater. 2016, 111, 766-773. [CrossRef]

40. CEN. EN 15978:2011-Sustainability of Construction Works-Assessment of Environmental Performance of Buildings_Calculation Method; CEN: Brussels, Belgium, 2011.

41. Hossain, M.U.; Poon, C.S.; Lo, I.M.C.; Cheng, J.C.P. Comparative environmental evaluation of aggregate production from recycled waste materials and virgin sources by LCA. Resour. Conserv. Recycl. 2016, 109, 67-77. [CrossRef]

42. Celik, K.; Meral, C.; Gursel, A.P.; Mehta, P.K.; Horvath, A.; Monteiro, P.J.M. Cement \& Concrete Composites Mechanical properties, durability, and life-cycle assessment of self-consolidating concrete mixtures made with blended portland cements containing fly ash and limestone powder. Cem. Concr. Compos. 2015, 56, 59-72. [CrossRef]

43. Borghi, G.; Pantini, S.; Rigamonti, L. Life cycle assessment of non-hazardous Construction and Demolition Waste (CDW) management in Lombardy Region (Italy). J. Clean. Prod. 2018, 184, 815-825. [CrossRef]

44. Pradhan, S.; Tiwari, B.R.; Kumar, S.; Barai, S.V. Comparative LCA of recycled and natural aggregate concrete using Particle Packing Method and conventional method of design mix. J. Clean. Prod. 2019, 228, 679-691. [CrossRef]

45. Van den Heede, P.; De Belie, N. Environmental impact and life cycle assessment (LCA) of traditional and 'green' concretes: Literature review and theoretical calculations. Cem. Concr. Compos. 2012, 34, 431-442. [CrossRef]

46. Grabois, T.M.; Cordeiro, G.C.; Filho, R.D.T. Fresh and hardened-state properties of self-compacting lightweight concrete reinforced with steel fibers. Constr. Build. Mater. 2016, 104, 284-292. [CrossRef]

47. Pedro, D.; de Brito, J.; Evangelista, L. Structural concrete with simultaneous incorporation of fine and coarse recycled concrete aggregates: Mechanical, durability and long-term properties. Constr. Build. Mater. 2017, 154, 294-309. [CrossRef]

48. Letelier, V.; Tarela, E.; Muñoz, P.; Moriconi, G. Combined effects of recycled hydrated cement and recycled aggregates on the mechanical properties of concrete. Constr. Build. Mater. 2017, 132, 365-375. [CrossRef]

49. Turk, J.; Cotič, Z.; Mladenovič, A.; Šajna, A. Environmental evaluation of green concretes versus conventional concrete by means of LCA. Waste Manag. 2015, 45, 194-205. [CrossRef]

50. Westerholm, M.; Lagerblad, B.; Silfwerbrand, J.; Forssberg, E. Influence of fine aggregate characteristics on the rheological properties of mortars. Cem. Concr. Compos. 2008, 30, 274-282. [CrossRef]

51. Torkittikul, P.; Chaipanich, A. Utilization of ceramic waste as fine aggregate within Portland cement and fly ash concretes. Cem. Concr. Compos. 2010, 32, 440-449. [CrossRef]

52. Singh, R.B.; Singh, B. Rheological behaviour of different grades of self-compacting concrete containing recycled aggregates. Constr. Build. Mater. 2018, 161, 354-364. [CrossRef]

53. Marinković, S.; Radonjanin, V.; Malešev, M.; Ignjatović, I. Comparative environmental assessment of natural and recycled aggregate concrete. Waste Manag. 2010, 30, 2255-2264. [CrossRef] [PubMed]

54. Knoeri, C.; Sanyé-Mengual, E.; Althaus, H.J. Comparative LCA of recycled and conventional concrete for structural applications. Int. J. Life Cycle Assess. 2013, 18, 909-918. [CrossRef]

Publisher's Note: MDPI stays neutral with regard to jurisdictional claims in published maps and institutional affiliations. 